\title{
Practitioners' views about equity within prenatal services
}

Priscilla Alderson (1) Bobbie Farsides (2) Clare Williams (3)

(1) Social Science Research Unit, Institute of Education, University of London

(2) Centre of Medical Law and Ethics, King's College, University of London.

(3) School of Nursing and Midwifery, King's College, University of London.

Sociology, 2004 38: 61-80.

\begin{abstract}
The British National Health Service (NHS) is based on principles of equal access, treatment and outcomes. This paper reviews health professionals' aims to provide equitable prenatal services and their views on whether women could be equal in their access to services, understanding during choice-making, and satisfaction about their care. Inequalities which compromise equity, conflicting meanings of equity, and the contribution of in-hospital ethics seminars to ethical health services are considered. Qualitative research combining sociological and philosophical methods investigated the experiences of health care staff attempting to provide equitable services and their practical and ethical problems. A total of 70 staff at a teaching hospital and a district general hospital took part in semi-structured interviews, followed by 11 innovative in-hospital ethics seminars based on themes derived from the interviews. The 56 seminar participants usually began with clear statements of their equitable aims but, encouraged by the health care ethicist, they went on to discuss their many concerns about obstacles which complicated the achievement of these aims. The sociological-ethics seminars provided unique opportunities for multi-disciplinary discussion of these inequalities and their impact on equitable intentions in health care. Analysis of the contradictions revealed during the seminars is guided by sociological theories that seek to explain the persistence of inequalities in health, and how NHS policies appear to perpetuate and increase them, despite practitioners' stated intentions to promote equality.
\end{abstract}

KEYWORDS inequalities, prenatal screening, decision making, ethics

Equity is almost unique in being widely endorsed as a moral value and yet attempts to define and achieve equity are contradictory and conflicting (Dworkin 1987; Singer 1979). The British National Health Service (NHS) was established in order to promote equity and since 1948 has promised equal access to health care (guided by clinically defined need and not, as formerly, by individuals' ability to pay) and equal treatment and outcomes. Fifty years later, however, considerable health inequalities prevail. Sociologists and epidemiologists report how inequalities in health are constantly reproduced, through numerous aspects of personal life-style and social structures, how the NHS's efforts to reduce inequalities are counteracted by these many complicating factors, and how public policies and interventions might alleviate and prevent them (Black et al 1980; Acheson 1998; Bartley et al. 1998; Marmot and Wilkinson 1999; Shaw et al 1999). Researchers also examine the cost-effectiveness of such interventions (Zoritch et al. 2000; Maclntyre et al.2001). Critical theorists assert that much research records but does not explain the processes and effects of health inequalities (Popay and Williams 1994; Scambler and Higgs 1999; Scambler 2001). 
Our research project entitled 'Cross currents in genetics and ethics at the millennium' investigated how the new genetics raises ethical dilemmas in everyday health services. The medical press is much concerned with applied genetics, but we found that practitioners did not yet consider there were obvious genetic (DNA based) components in pre- and post-natal and related services. However, networks and routines are in place (Coventry and Pickstone 1999) ready for genetic knowledge and techniques to be applied extensively, as they become available. For example, at present, fetal tissue can be obtained only through costly, risky and invasive methods. If efforts to isolate fetal cells in maternal blood succeed, DNA screening tests for numerous genetic conditions are likely to be offered routinely when the new technique obtains fetal DNA through a simple maternal blood test, which is already routine for other purposes. Like mass prenatal screening, mass genetic services are likely to be introduced without public debate (Kerr and Shakespeare 2002), and we asked practitioners what questions they would ask before such services are introduced. We had not expected practitioners to be so preoccupied with 'old' still unresolved dilemmas. Analysis of the themes raised during 70 semi-structured interviews found current inequalities to be a dominant political-personal concern. The interviews were partly used to prepare discussion themes for 11 in-hospital multi disciplinary seminars facilitated by an ethicist. This paper reviews the seminar discussions about the dominant theme of equity, and how current inequalities might be moderated or amplified through new genetic services. Equitable services are taken here to be fair, balanced, non-discriminatory, equally presented and distributed, and therefore mainly standardised.

The aims of this paper are: to supplement the largely macro research on health inequalities with detailed micro examples of health practitioners' reported views and experiences; to examine practitioners' and managers' views about their intentions to promote health equalities, and how these intentions translate into everyday practice within the constraints of the NHS and related social structures; to explore contradictions between claims to promote equity, and services which can perpetuate inequalities, with the views of staff on how they manage the ensuing tensions and uncertainties; to consider how sociological theories explain why prenatal services perpetuate inequalities in health.

\section{Combining sociology and ethics}

Wheale (1998:171) reviews inherent ambiguities and inconsistencies in principles such as equity to illustrate how, although they are usually discussed as if they are based on a firm equilibrium and consensus of legal and ethical values, a consensus does not exist. He concludes that bioethical principles are based on unacknowledged disequilibrium, when there are no obvious rules for reconciling conflicting principles. This may explain why our seminar participants tended to begin with confident optimism, affirming their unanimous aim to provide equitable services, then gradually to express doubts and anxieties, contradictions and practical difficulties which thwarted their aim.

The seminars were designed to introduce explicit ethics analysis into inter-disciplinary discussions among practitioners about their daily concerns. Many social scientists criticise ethics as a self-interested, powerful discourse, exploited by scientists and doctors to serve their own ends, such as through medically dominated research ethics committee. When ethicists, like scientists, abstract, atomise, de-politicise, over-simplify and universalise the issues they study, then human agency and relationships - the fabric of ethics - can lose their inherent meaning and value (Weisz 1990; Stacey 2002). When ethicists mystify and obscure questions of power and morality, they can exclude supposedly ignorant 'lay' people from debate. Conservative ethicists endorse instead of critically challenging innovations in technoeugenics (Parens 1998; Webster and Nelis 1999; Alderson 2002). However, our research aimed to investigate how strengths in critical ethical analysis, its methods of revealing the logic and structures underlying common arguments, and of probing and challenging people's 
views on ethical dilemmas, could be useful for sociological data collection and analysis, and for increasing practitioners' own shared understandings. We avoided the usual method of analysing brief impersonal case studies to teach ethical expertise. Instead, the ethicist, originally a political philosopher, became immersed in the practitioners' own complicated personal and political concerns through reading transcripts of their individual interviews before the seminars, and by addressing issues they raised. She aimed to help practitioners to use ethics skills critically and, unusually, to reach 'the deep structure of bioethics' (Fox 2002:249) through practical rather than abstractly theoretical sessions.

\section{Expanding genetic services}

Until genetic treatments are developed and tested, and apart from opt-in use of specialist genetic life-style advice, genetic knowledge is applied most directly in prenatal screening. Experts in genetics distance eugenics from the current prenatal services, by contrasting former public state-enforced eugenics with today's personal, prenatal choices (Kerr et al 1998) although research repeatedly shows how women can experience these choices as oppressive rather than liberating. The choice is not free when women feel that refusing termination of pregnancy for fetal anomaly leaves them with great responsibility but little power or support, and potentially with disapproval and social exclusion (Rapp 1999; Lippmann 1994; Kaufert 2000). Economic policies, such as whether society values and supports disabled lives or funds screening services intended to prevent such lives, are transformed into personal prenatal choices and private griefs for women to bear (Beck 1992; Green and Statham 1996; Santalahti 1998; Asch 2000). The process conceals political and economic pressures, thus making these pressures harder to challenge or even to recognise, and thus more powerful (Lukes 1974). The transfer of responsibility for decisions, with attendant guilt and blame, from policy makers or 'society' on to each individual pregnant woman paradoxically frees and also burdens and constrains women. The transfer can obscure how social inequalities (of income and education) may be increased instead of reduced in the way services are unequally received. These difficulties undermine and contradict prenatal practitioners' claims to value each woman's right to choose, and to have equitable (unbiased, non-discriminatory and non-stigmatising) information about health and disability (Alderson 2001).

Illich (1976:91) warned that, in industrial societies, all aspects of people's lives would increasingly fall under institutional control, as personal functions were assigned to impersonal institutions. Institutional controls expand through dragnets, when services such as antenatal care and genetic counselling designed for those with exceptional needs become routine mass services. As services expand, resources are controlled by professional providers who mystify and appropriate personal autonomy, by transforming people into the dependent clients of experts (medical and midwifery staff, sonographers, geneticists, laboratory technicians, epidemiologists, statisticians and health economists) who calculate, explain and manage risks. This transfer of power is rationalised as fulfilling needs. New techniques create new 'needs' and 'demands'. Simultaneously, life world (Habermas 1987) ethical problems (such as how to respond to the prospect of having an impaired child) are transformed into system and technical ones, which can be 'repaired' by the professionals, such as by offering to terminate the pregnancy. Marketing technical repair of perceived need does not prevent or eliminate need; instead, it assigns, for example, all pregnant women to a needy dependent state. Social control judges people by their levels of conformity to and consumption of the services. Expanding prenatal services can increase inequality: between women with different levels of income, informed understanding, scope to choose and to 'consume' the services; and between the expert providers and dependent users of services. 
Ambiguities for NHS staff

Research has concentrated on pregnant women's responses to these dilemmas, with some surveys of practitioners' views. However, there has been little qualitative research into prenatal practitioners' reflections during interviews or group discussions on their ethical dilemmas in daily practice. No prenatal research, that we know of, has used our combination of sociological and philosophical methods of data collection and analysis

Many prenatal practitioners and managers appeared to be caught in stressful ambiguities between structure and agency, the system and the life world, the technical and the social. They were trying to meet their obligations to each, to respect the life worlds of their clients but without time to learn about and respond to these, and to respect their own life world and values in a system that exhorted them to deny these by being 'non-directive'.

Traditional NHS priorities to treat individuals' illness and injury in order to restore health (and thus, potentially, health equality) is shifting towards public health efforts to predict and prevent morbidity in 'healthy populations'. There is concern that new disadvantaged classes with untreatable genetic conditions are being created. 'Preventive' health services may aim to prevent public expenditure as much as disease (House of Commons 1995).

Prenatal policies that privatise choice can compound inequalities of class, ethnicity and gender through the growing feminisation of poverty, when women are tacitly encouraged to feel personally responsible if they 'choose' to have a disabled child (Beck 1992). The rhetoric of free consumer choice ignores commercial interests that promote potentially profitable screening and genetic technologies (Kaufert 2000; Scambler 2001). For example the lead author of government sponsored reports on screening directs the relevant software company (Wald et al. 1998). Health service users are not treated as citizens who share in planning services with some regard for shared interests and equity, but as consumers who indiscriminately demand ever more services (Hill and Michael 1998). Practitioners can then feel forced to respond to consumer demands, suspending their professional judgements about efficacy and morality, particularly in screening services for 'healthy' people. When offering effective treatments for disease, practitioners are in a stronger position to give advice, and to withhold treatments considered to be futile or harmful. Significantly, an intensive care neonatal nurse said she was unfamiliar with her prenatal colleagues' use of the term 'non-directive counselling' as part of clinical care. We investigated practitioners' views about their part in advancing new technologies and promoting equity. When asked who drove the expansion of prenatal services, they tended to imply that they felt powerless, and to transfer agency (Brown, Rappert and Webster 2000) to 'government policy', 'we're agents of the state', 'it is public demand'. They linked screening for Down's syndrome with 'state' policies to economise on care services. They tended not to see themselves as actively furthering these expansions by implementing them, although the ethicist asked:

When empathising with [women] and getting into their heads, I suppose you can't forget that you're part of the system that has built up this opportunity for screening? You value it - you see it has a purpose - you see that it achieves something?....In this renowned centre ....it's an endorsement whether you sell it to them [to have a prenatal test] or not.

Practitioners emphasised how they aimed to mediate prenatal policies and hard choices by supporting women as humanely as possible. Some practitioners felt oppressed by constraints of time and resources, and by obligations to transfer responsibility for choicemaking on to the pregnant women who were sometimes confused or reluctant, anxious or resistant. Some midwives reported sharing these feelings.

\section{$\underline{\text { Research methods }}$}


Eleven seminars, approximately two hours long, were led by an ethicist (BF) and observed by two sociologists (PA and CW) who had previously interviewed 70 staff. Fifty-six obstetric, neonatal, haematology, paediatric, scientific, community and management staff attended during 1999-2000; 12 asked to attend twice, making a total of 68 attendances. The settings were a teaching hospital A and a district general hospital B. Senior staff supported the application for research ethics committee approval, and encouraged staff to attend the seminars. Participants were given an information leaflet about the research and the seminar, listing: each person's name, discipline and post; aims and agenda of the seminar; a note on confidentiality asking people not to repeat names outside the meeting; a request to tape record the session; assurance that names and identifying details would be removed from transcripts, and that people could request for any of their comments also to be deleted; a note that they would be asked later for their evaluations; and details of how to contact the researchers.

Disciplines and staff grades were deliberately mixed, cutting across specialties, professions and hierarchies. There is not space in this paper to analyse the responses by occupation, experience or hierarchy, or how inequalities between health service staff, of education, gender and ethnicity (Stacey 1988; Ahmad 1993) were explicitly and implicitly demonstrated and discussed by the attenders. Inequalities among staff can undermine their advocacy for patients, by compounding inequalities among their patients, such as being women, poor and black. Policy makers tend to be shielded from the problems arising from their decisions if they are remote from the intermediaries, such as junior midwives, who implement the policies. 'Remote' may mean having too little time and space for adequate discussion, as well as being the manager who hires and fires the junior staff who may then be deterred from reporting problems. Approachable and sympathetic senior staff can be unwillingly distanced from juniors by such routines and structures. The seminars attempted to overcome some of these barriers and achieve more equitable cross-disciplinary discussion by offering a 'safe' meeting space.

Before the seminars, the 70 interview transcripts were analysed by content for emergent themes which were then coded (Weber 1990; Strauss and Corbin 1990). The research team met regularly to analyse the data, combining sociological and ethical perspectives to enrich and validate the analysis. In stage 2 of the analysis, for this paper, all references in the seminar transcripts to equity and inequality were classified into the sub-themes - inequalities in the use of services and time, information and understanding, and decision making (also ethnicity and religion not reported here). The sub-themes provide the following subheadings under which practitioners' key concerns will be reviewed: daily practical inequalities and how these might be reduced or amplified in new genetics services; whether, and how, mass genetic services should planned; how equitable aims are thwarted by contradictions and practical difficulties; tensions between political structures and personal agency; contradictions in services intended to liberate but which construct needy dependence and compliance; the practitioners' part in advancing potential genetic technologies; and whether the women could be equal in their use of services. Speakers are anonymised by a number and by a deliberately broad title. For example, 'obstetrician' refers to consultants, registrars, research fellows, and specialists in fetal medicine.

Unequal use of services and time

The ethicist commented that the hospitals were egalitarian in offering Down's syndrome screening to every woman and not, as in some hospitals, only to women over a certain age. Some participants compared their hospital favourably with others which refused tests to younger women or might pressure older ones to have amniocentesis. However, many people began to discuss tensions between notional ideals of equal access, opportunities and outcomes for health service users, and the unequal realities which compromise practitioners' 
equitable aims. The ideals of standard and of tailored care conflict. As a health visitor (62) noted: 'There isn't an average woman and there's a huge variety of reactions to screening'. A midwife(8) thought that though the service 'seems to be very egalitarian [it may not be because women] don't all come from the same starting point'. Midwife (46): 'It depends on their background and how much they have read, and you get women who want....want every sort of single screening test available to enable them to obviously make a choice and to have a perfect child'.

Staff at hospital B noted that women in higher socio-economic groups were more likely than other women to travel to a nearby specialist centre rather than attend hospital $\mathrm{B}$, a pattern which reinforced unequal health care systems. Some hospital B midwives after attending courses at centres which offered extra tests, said they believed that they must inform every patient about her right to travel to buy these extra tests at other centres. The values of equity thus supported an advertising process, which increased inequalities between women who did or did not have the requisite time, income or assertiveness.

Midwife (51): We don't offer some of the tests here but we have to say if you went to this other centre and paid they could offer you these tests....so you are getting a divide between the rich and the poor, so what outcomes will you get in those different groups?

Manager (45): You have got to stick within the budget....but as long as you have made the offer of where the facilities can be sought, that's as far as you can go.

Managers were concerned about pressure to offer more tests within already tight budgets. Yet they believed that every hospital had to compete to offer tests that were already available at other hospitals, in the name of equity and also to avoid losing staff, credibility and patients. Manager (45): 'I just wanted to make it fair to our clients really'.

Participants expressed great concern about lack of time. It 'is the dilemma we are grappling with, and personally I think screening has been introduced without the resource commitment being taken on board' to ensure adequate support. This senior manager (42) felt that screening often occurred before women had time to become informed. As new conditions begin to be screened for routinely, treating everyone equally involves squeezing even more information into already packed allocated time. Many midwives spoke of the 'unsatisfactory nature' of this rapid exchange during antenatal booking interviews, further compressed by the added difficulties of ensuring that adequate medico-legal records were kept. To be fair to everyone they had to rush almost everyone. Equal basic information for all was given sometimes at the cost of individual relevance and need. Manager (27): 'And I agree, with the resources you've got available, there is no more time'.

Some midwives described 'breathing a sigh of relief' when a woman said she had read the leaflet, even if they suspected that she might not have, because they could save time on explanations.

Unequal need among pregnant women led staff to borrow time from some to give extra time to others.

Midwife (8): You don't have the same luxury with the ones that are normal and easy....But [with] somebody with an abnormality, yes, I think you do have that luxury because you do spend more time with them. You appreciate that this is a very difficult time for them.

Equal access during pregnancy also depends on women arriving at the 'right' time during their nine months for certain services, or they could not benefit from the 'ideal' routine. Disadvantaged women were more likely to arrive >late'. 
Unequal information-giving and understanding

Knowledge among women in the clinics ranged from those who 'read everything and surfed the internet', or who knew people with screened-for conditions, to those who had not read the brief clinic leaflet and would ask the most basic questions, such as, 'What does Down's syndrome mean?' They could not be treated equally in the sense of uniformly. Practitioners described how they rapidly 'gauged' how to pitch information to suit each women's understanding and educational background. Yet they knew that such gauging risked working with misleading and discriminatory stereotypes when aiming for equal outcomes rather than equal provision. A midwife (29) warned of people's diverse, unpredictable responses, and the ethicist replied.

Ethicist: So beware of stereotypes?

Midwife (29): Absolutely! But we do it every single day, and it's ridiculous.

Haematologist (10): I think we have to do it to a certain extent, otherwise it would be so complicated.

(Quotations set together in one paragraph record discussion sequences.)

The haematologist went on to describe steering between over-generalising and overindividualising in his efforts to respond sensitively to people's cultural values.

Participants disagreed about whether it is possible to give equal standardised information to each woman. One midwife (1) said that she began 'explaining exactly the same as I do with everybody, even though I know the outcome is going to be different, you do get the occasional one who does surprise you'. In the following exchange, a manager favoured standard less personal information whereas a practitioner was possibly more realistic.

Manager (27): Hopefully it's not biased information [about screening] and it's information based on facts and not your personal, just your personal beliefs....

Midwife (31): It's like any piece of paper, if you have ten minutes to discuss this with somebody you're going to pick out what you perceive that you want that particular person to know....based on your personal beliefs however much you think you're not judgmental....

A midwife (78) said that information 'does vary enormously from midwife to midwife...and is very dependent on the communication skills of that particular midwife'. Information also depends on continuity of care because gaps may be left when staff assume that others have given that information. Practitioners added examples of informing the same couple twice using slightly different terms which led them to make different decisions. Some participants expressed concern that they could too easily influence and persuade couples.

One obstetrician (36) questioned how to reconcile the demands for ever more detailed information with the requirements 'that it should be made understandable as well, which is extremely difficult'. Two other obstetricians felt that clearly agreed prior consent to potential interventions enables women to be more aware of 'what they are going for', helps to reduce ignorance and shock about interventions (13), and can 'forge some sort of understanding' and a 'much truer partnership' (72). Again they raised tensions, discussed through the seminars between recommended and realistic practices. These were compromised by a basic misunderstanding: the staff often described women as assuming that the purpose of ultrasound scans was >to bond with the baby' and 'to check that everything is all right' and then being shocked to realise that the scanners' main purpose was to search for pathology for which usually the only treatment was to offer termination. Staff debated the ethics of giving honest but unrequested and possibly unwanted information. 
A psychologist (22) continued the theme that 'society' insisted on having, more and more information, by saying: 'I think it's unethical to withhold information'. Yet staff frequently discussed inequalities in how women understand, interpret and cope with information. Varying misunderstandings needed to be unravelled. Some women were seen as overoptimistic of having a 'perfect child', and different women interpreted the same risk level as very high or very low, thus requiring widely different kinds of explanations.

Midwife (7) Whatever you say, some people, their pregnancy will be ruined with worry, but that's not the same for everybody. Yes, it's very difficult....For some people the most basic explanation - the idea of screening and statistics they'll never be in a position to really understand.

Some staff questioned the overall benefit of informing everyone about fairly rare risks.

Obstetrician (71): Are you truly going to worry 99 per cent of the patients....is it right or wrong? My feeling is that the balance is wrong. You worry too many people for the sake of the few....

Haematologist (10) You've got to think of >first do no harm' and are you doing more harm than good by telling people these things [and meanwhile not having time] to be explaining the other more important things?

Information leaflets posed irresolvable problems of inequality in their compromises between encapsulating sufficient essential information which was also clear and brief, especially given the uncertainty about what knowledge each reader wanted.

Midwife (50): [Even] for someone professional, it's really hard to try and read it....and it's supposed to be in plain English, but the statistics and risk factors are hard to pick up. We've got it translated into different languages as well, but -.

These examples illustrate how staff felt they had to juggle compromises between under- or over-informing each woman. Practical notions of equity served as flexible guides rather than uniform protocols.

\section{Unequally shared decision making}

Whereas some women were said to come in knowing and 'demanding' what they want 'they come with their mind made up', others feel ambivalent and need much more time and help before they can decide. Small decisions may lead on to momentous ones. Deciding to have a scan may lead to further tests with the possibility of elective termination or inadvertent miscarriage. Women are unequal in how they foresee and choose this process, or unwittingly begin on it through being under-informed. Some of the staff vividly described the tensions of trying to provide high quality 'appropriate' care within severe time constraints.

Sonographer (40): Now theoretically they've all received a leaflet beforehand and they've sat and read all the information again in the clinic, before they're brought through for their scan. But in reality, because you've got time constraints that isn't necessarily the case. A lot of women will have signed the form but when you explain it to them again they decide they don't want to have it, you know. So you've got a form signed saying, 'Yes, I want to have an invasive test and a blood test,' but then you discuss it with them, and they think, 'Oh well, I don't want to have that because I don't want to deal with the implications of that.' So - it is very difficult.... 
Surrounding practitioners' anxiety about ensuring that women were adequately informed was uncertainty about the purpose and benefits of screening programmes. While some people were convinced that the option to avoid having a seriously impaired child justified all the costs and anxieties generated by the programmes, others were less sure, and they used the seminars as a safe forum to raise their doubts about the ethics and future developments of screening. A senior manager (42) said:

As a profession we've introduced this enormous process of screening....and if we just let whatever happens happen.... just think that would be so wrong...you have to take some responsibility....making sure that the thing doesn't get completely out of control in some respects....[When] we say 'If a woman wants something she can have it,' I think that denies our own responsibility for making sure that medicine is practised, I don't know whether the word is, ethically.

Practitioners debated how engaged they ought to become in women's decision making. Should they leave women to make 'free' choices or, when patients requested help, should they be more directive or give a personal view (Williams et al 2001a). The unequal degrees of engagement reported by the staff were further varied by patients' preferences and by how firmly women appeared to be able to request extra help. Practitioners also varied in how much they challenged women to be definite and responsible about their decisions. One midwife (31) described how much of her time was spent with women who expressed informed refusal. 'They're well read, they've got friends that are doctors, whatever, they know it all, they know all the tests that are available and they feel they shouldn't have it. But yet they're asking you to sort of justify why they shouldn't have it'.

Informed consent involves a legal transfer of knowledge and the acceptance of risk from the clinician to the patient. A midwife (31) was concerned that she might not always effect this transfer of responsibility.

But sometimes, it's all to do with time and you often feel that however limited your time is you have to get your information across to that person. And I know from my own, my own self, that I thought that if I don't get that information correctly across to them the decision that they make would rest on me.

As frequently happened, this point was expressed emotionally, as if the speaker shared her patients' unease. Participants frequently described mass care as involving its own momentum and pressures, and a few mentioned experiencing this during their own pregnancies. A paediatrician (58) who refused some screening tests for herself felt that, $>$ They all looked at me as though I was completely mad'. One manager (57) agreed, saying she had felt unable to refuse, and another manager (45) added, 'You have to quite tough to refuse....it's almost written everywhere Adifficult woman@....you have to be very strong because every time you come to the clinic somebody says something'.

Efforts to treat everyone equitably risk imposing rigid conformity. This was illustrated by the groups' discussion of their different standards for consent versus refusal and how they accepted consent with little record keeping, but questioned and 'wrote reams' if women refused mainly, they said, from anxiety about litigation if women changed their mind. A midwife added 'are we just protecting ourselves?' pointing to the imbalance of time and resources expended in clinics to promote and protect medico-legal agendas rather, possibly, than to be guided by women's preferences.

A further irreconcilable paradox for some staff was that equitable prenatal services support women's rights but also constrain them. 'Screening must carry on, it's women's rights'. (Midwife 30). However, decisions about introducing prenatal screening services are strongly 
influenced by men (obstetricians, senior policy makers, equipment manufacturers), but are used and mainly conducted by women.

Midwife (47): The Department of Health have said, >You have got to reach these [HIV screening] targets by such and such a time'. And there are some hospitals that have gone ahead and done screening and have got a very good uptake. [Should women's 'informed consent' include telling them] the whole thing [such as whether you are] just doing [screening] to get your targets up so that your purchasers are happy and things like that? It's just the whole catch 22 situation and you are thinking well if you don't offer and you don't give the woman the complete history behind the reason why you are offering the test, what are you then doing?

Another midwife (78) asked, '[Are we] putting emotional pressure on her to have a test she doesn't want, for our benefit?' A manager (67) agreed saying:

Who are the tests for? And the Department of Health continually push hospitals to perform to their targets, but somewhere in there, there is an individual and they seem to be lost...I've become quite worried about the dictatorship of experts because we know what's best and an awful lot of pressure can be put on someone. Patient choice is so crucial and it's taken a very long time for women to fight to have the right to say what happens with their bodies, and it becomes very difficult.

\section{Discussion}

This final section considers combining research in sociology and ethics, links between current prenatal services and future genetic services, and how sociological theory can explain key problems of equity and power raised in the seminars. The research, conducted in only two hospitals, is not representative so that our conclusions are necessarily circumspect, although the hospitals varied from local district hospital to leading specialist centre, and common concerns were expressed by staff in both settings. These arose from the structural organisation of the services, thus indicating that the concerns may be widely held among prenatal staff. This paper examines practitioners' reported perceptions about ethical dilemmas during the seminars and not report our ethnographic observations or interviews or use conversation analytic methods

\section{Combining sociology and ethics}

The rubric 'ethics seminar' attracted a wide range of practitioners. Nurses commented that doctors who avoided psychological 'staff support' sessions willingly attended the ethics seminars, which ranged over many topics and moods: critical debate, anxiety and doubt, frustration, optimism and humour. Many were explicit about their pressing uncertainties on how to resolve contradictions about equity, and the meanings of human obligations to their patients when raising momentous life-death decisions with them.

We suggest that the prior sociological interviews strengthened the philosophical discussions and their practical relevance by grounding them in the staff's key concerns and routines. During their evaluations, many staff expressed interest, even surprise, about the value and relevance of applying critical ethics to their work (Alderson et al. 2002). Some practitioners spoke of relief at being able to share their anxieties, and to realise that senior colleagues also felt them, as if the seminars broke a silence on these issues. The ethicist contributed to the sociological data collection and analysis through promoting probing though non-threatening analysis and clear logical frameworks in the seminars. By respecting their professed ethical standards, she could explore with practitioners the numerous practical difficulties they faced in efforts to achieve their partly incompatible and unachievable ideals. 
The seminars illustrated the value of providing time and space for critical reflection informed by the differing expertise of senior and junior, management and clinical staff, which we aimed to exploit through our research design.

Prenatal and genetic services

The repeated concerns, about worrying 'too many people for the sake of the few' with information of questionable benefit, were raised by staff. Mass prenatal services are not yet genetic (in using DNA analysis) but they do have characteristics which mass genetic services are likely to have: screening of low risk 'healthy' populations; junior staff with little clinical or practical knowledge about the numerous conditions screened for; limited time and resources for informed discussion; >patients' who may be unaware that a simple test (ultrasound scan or blood test) could check for many fetal conditions with no known cure or certainty about their potential severity and impact; equitable aims of accessibility and non-discrimination but within inequalities which practitioners cannot rectify, especially given the immense diversity of women they care for; rapid expansion of established structures and routines with little public consultation, extra planning or debate about alternative uses of the limited resources.

During debates about cloning human embryos during autumn 1999, politicians said that technology had overtaken ethics: even if a solution to today's dilemmas could be found, it would be overtaken by tomorrow's innovations. Before genetic prenatal services are introduced, current knowledge and methods in sociology and ethics could be combined and applied more widely to examine the ethical, economic, political and social realities of such innovations, in order to inform policy making.

\section{Equity and power}

The seminars raised paradoxes. In the name of rational choice, the rapid expansion of under-resourced services left practitioners, patients and even policy makers still less time and scope to make rational choices. In the name of freeing women (from the burden of unwanted children), services were provided that many staff experienced as oppressive for practitioners and patients. In trying to be humane mediators, staff might obscure problems and prop up services in need of reform. The dragnet (Illich 1976), intended to benefit everyone equally, treats all pregnancies as potentially pathological and needy, drawing pregnant women into anxious dependence on expert medical risk management. For many people, the more they consume medico-legal risk managing services, the more they want the perceived protection of further services. Aims to promote universal access to screening, as beneficial and necessary, conflict with respect for women's informed refusal as a rational choice (Williams et al 2001a, 2001b, 2002).

Many practitioners described trying to promote equity but appearing to perpetuate inequalities. The seminars provided a rare opportunity for them to acknowledge this. They showed how practitioners tended to attribute problems to their own personal limitations, or to women's difficulties in understanding, rather than questioning the whole system. However, excellence in equitable mass care conflicts with excellence in personally tailored care; equal, standardised services cannot suit widely diverse needs. How could practitioners achieve equal outcomes, such as free choice for everyone that includes the option not to receive available services? How could practitioners be non-discriminatory yet also rapidly identify different types of women, guided partly by sometimes discriminatory stereotypes? Could they respect all women's rights whilst also perhaps pressing unwilling women to make choices? Equal access was offered in theory, but without the extra practical help which disadvantaged women needed, such as transport to specialist centres, if they were to use offered services. English-speaking well-educated women were confused by the information, which overwhelmed and often confused others even more when they lacked compensatory information services. 
The inequities and contradictions cannot be explained simply by describing empirical experiences. Scambler and Higgs (1999) and Scambler (2001:111-3) argue for moving beyond positivist research that aims to predict health inequalities by studying variables. They advance the importance of explaining the continuance of health inequalities through three related types of sociological innovation: theoretical, conceptual and methodological. This entails not merely recording the 'webs of causation' and risk factors for health inequalities, but searching for the active powerful 'spider' spinning the webs (Krieger 1994:899 cited in Scambler 2001;108). Scambler and Higgs draw on Bhaskar's (1989) thesis of the reality of 'beneath the surface' objects, such as class relations, which are accessible/observable only in their surface effects in 'open' systems, in order to theorise the salience, to inequalities in health, of the power elite (government, policy makers) that is >informed and harried by the capitalist elite'(commerce, industry) (Scambler 2001:108). Bhaskar's conceptualisation of dynamic class relations can inform explanations about continuing inequalities. Rather than seeing class relations as fixed entities, for example, these are theorised as dynamic interacting layers of factors and influences, (Popay et al. 1998) and divisions between those who control the means of production and those who do not. Prenatally, control is transferred from the reproducing women to the managers of the new reproductive technologies and systems. Services of great potential benefit to a few women with particular needs are imposed on all in the name of equity. Methodologically, sociologists are urged to move beyond positivist collection of surface data and invariant empirical regularities, and to generate and test theories. In exploratory and so far under-researched sociological investigation of 'the how as well as the whyYof health inequalities [these may be understood as] indirect (and largely unintended) consequences of the behaviours of members of the power elite informed by the capitalist executive' (Scambler 2001:113-4). Health inequalities are less categories or structures than historical phenomena that can be shown to happen in human relations (Thompson 1963). Among numerous mechanisms, the elite control the means of production and profit and, as the system, they colonise the life world, by absorbing it into the political/economic system, and turning social issues into technical ones (Habermas 1987) in ways described throughout this paper. Predictions about future effects of fetal impairments were divorced from the social context, the life world, of the future child and of creative human agency, and were reduced by a commercial system into biological >facts' with cost-effective technical fixes.

The discussions about contradictory attempts to define and promote equity revealed deeper tensions about where the NHS staff believed they should stand. In sociological terms (that they did not use explicitly), in effect, they debated their loyalty to the system, to the life world, or to some limbo in between. A few people held a confident position but, for many, their dilemmas appeared to be increased in that these were seldom acknowledged or discussed, and so tended to be felt as personal failures. Participants combined claims to promote equity with reviews of activities that even some consultants and senior managers described as potentially having very uncertain, negative or harmful effects. Health research tends to assess the visible problems of anxiety and to recommend more supporting services, but this can simply increase problems if the deeper underlying ones of unequal control and class relations continue unacknowledged. The ethics seminars, complemented with sociological interviews and analysis, offered a forum for small groups to explore these ambiguities in a practical and political context.

\section{Acknowledgements}

We are grateful to everyone who took part in the seminars, to the Wellcome Trust Bioethics Initiative for funding the research project, 'Cross Currents in Genetics and Ethics around the Millennium 1999-2001', no. 056009, and to the editors of Sociology and three anonymous reviewers. 
$\underline{\text { References }}$

Acheson, D. (1998) Independent Inquiry into Inequalities in Health. London: Stationery Office.

Ahmad, W. (1993). 'Promoting equitable health and health care: a case for action', in W. Ahmad (ed), >Race' and Health in Contemporary Britain. Buckingham: Open University Press, pp. 201-41.

Alderson, P., (2001) Down's syndrome: cost, quality and value of life. Social Science and Medicine, 53:627-38.Alderson, P. (2002) The new genetics: promise or threat to children? Bulletin of Medical Ethics, 176: 13-18.

Alderson, P., Farsides, B., Williams, C. (2002) Examining ethics in practice: health service professionals' evaluations of in-hospital ethics seminars Nursing Ethics 9,5:518-31.

Asch, A. (1999). 'Prenatal Diagnosis and Selective Abortion: a Challenge to Policy and Practice'. American Journal of Public Health 89, 11:1649-57.

Bartley, M., Blane, D., Davey Smith, G. (1998) Introduction: beyond the Black Report. Sociology of Health and IIIness, 20, 5: 563-77.

Bhaskar, R. (1989) Reclaiming reality. London: Verso.

Beck, U. (1992). The Risk Society: Towards a New Modernity. London: Sage.

Black, D., Morris, J., Smith, C., Townsend, P. (1980) Inequalities in Health: Report of a Working Party. London: Department of Health and Social Security.

Brown, N., Rappert, B. and Webster A. (Eds.) 2000. Contested Futures: a Sociology of Prospective Techno-Science. Aldershot: Ashgate.

Coventry, P. and Pickstone, J. (1999) From what and why did genetics emerge as a medical specialism in the 1970s in the UK? Social Science \& Medicine 49:1227-38.

Dworkin, R. (1987). Taking Rights Seriously. London: Duckworth, chapter 6, Justice and rights, pp 150-184.

Fox, R. (2002) Medical uncertainty revisited. In Bendelow, G., Carpenter, M., Vautier, C., Williams, S. (Eds) Gender, Health and Healing. London: Routledge/Falmer, 236-253.

Green, J. and. Statham, H. (1996). 'Testing Pregnancy', in T. Marteau and M. Richards (eds.) The Troubled Helix. Cambridge: Cambridge University Press.

Habermas, J. (1987) The theory of communicative action, vol 2: Lifeworld and system: a critique of functionalist reason. Cambridge: Polity Press.

Hill, A. and Michael, M. (1998). `Engineering Acceptance', in P. Wheale, R. Von Schomberg and P. Glasner P (eds.) (1998). The Social Management of Genetic Engineering. Aldershot: Ashgate.

House of Commons Science and Technology Committee. (1995). Human Genetics: the Science and its Consequence. London: HMSO.

Illich, I. (1976) Limits to Medicine. Medical Nemesis: the Expropriation of Health. London: McClelland and Stewart.

Kaufert, P. (2000). 'Health Policy and the New Genetics', Social Science \& Medicine, 51: 821-9.

Kerr, A., Cunningham-Burley, S. and Amos, A. (1998). 'Eugenics and the New Genetics in Britain: Examining Contemporary Professionals' Accounts', Science, Technology \& Human Values, 23, 2:175-198.

Kerr, A. and Shakespeare, T. (2002) Genetic politics: from eugenics to genome. Cheltenham: New Clarion Press.

Lippman, A. (1994) 'Prenatal Testing and Screening: Constructing Needs and Reinforcing Inequalities', in A. Clarke (ed.) Introduction to Genetic Counselling: Practice and Principles. London; Routledge.

Macintyre, S., Chalmers, I., Horton, R., Smith,R. (2001) Using evidence to inform health policy: case study. British Medical Journal, 322:222-5. 
Marmot, M., and Wilkinson, R. (eds) (1999) Social Determinants of Health. Oxford: Oxford University Press.

Paul, D. (1992). 'Eugenic Anxieties, Social Realities and Political Choices', Social Research, 59:663-83.

Parents, E. (Ed.) (1998) Enhancing human traits: ethical and social implications. Washington DC: Georgetown University Press.

Popay, J. and Williams, G. (eds) (1994) Researching the People's Health. London:

Routledge.

Popay, J., Williams, G., Thomas, C., Gatrell, A. (1998) Theorising inequalities in health: the place of lay knowledge. Sociology of Health and IIIness, 20, 5: 619-44.

Rapp, R. (1999). Testing women, testing the fetus. London: Routledge.

Santalahti, P. (1998). Prenatal Screening in Finland. Helsinki: STAKES.

Scambler, G. (2001) Class, power and the durability of health inequalities. In Scambler, G. (ed) Habermas, Critical Theory and Health. London: Routledge, 886-118.

Scambler, G. and Higgs, P. (1999). 'Stratification, Class and Health: Class Relations and Health Inequalities in High Modernity', Sociology, 33:275-96.

Shaw, M., Dorling, D., Gordon, D., and Davey Smith G. (1999) The Widening Gap: Health Inequalities and Policy in Britain. Bristol: Policy Press.

Stacey, M., (2002) Concluding comments. In Bendelow, G., Carpenter, M., Vautier, C., Williams, S. (Eds) Gender, Health and Healing. London: Routledge/Falmer, 267-283.

Strauss, A, and Corbin, J. (1990). Basics of Qualitative Research. London; Sage.

Singer, P. (1979). Practical Ethics. Cambridge: Cambridge University Press.

Thompson, E.P. (1963) The making of the English working class. Harmondsworth: Penguin. Wald, N., Kennard, A., Hackshaw, A. and, McGuire, A. (1998). Antenatal Screening for Down's Syndrome. Southampton: Health Technology Assessment, NHS R\&D HTA Programme, 2,1 .

Weber, R. (1990) Basic content analysis. London: Sage.

Webster, A. and Nelis, A. (1999) Regulating the gene. Health, risk and society, 1,3:301-312. Weisz, G. (ed) (1990) Social science perspectives on medical ethics. Dordrecht: Kluwer. Wheale, P. (1998) 'Some Moral and Legal Implications of the New Genetics for the Foetus', in P. Wheale, R. Von Schomberg and P. Glasner (eds.) The Social Management of Genetic Engineering. Aldershot: Ashgate, pp 159-174.

Williams, C., Farsides, B., Alderson, P. (2002) 'Dilemmas encountered by health practitioners offering nuchal translucency screening: a qualitative case study.' Prenatal diagnosis,22,3:216-20.

Williams, C., Alderson, P., Farsides, B. (2001a) 'Is non-directiveness possible within the context of antenatal screening and testing?' Social Science \& Medicine, 54, 13:17-25.

Williams, C., Farsides, B., Alderson, P. (2001b) 'Conflicting perceptions of the fetus: person, patient, 'nobody', commodity?' New Genetics \& Society, 20,3:225-238. 